\title{
A STUDY ON ACHIEVEMENT MOTIVATION OF HIGHER SECONDARY STUDENTS
}

\section{VENKATARAMAN S \& MANIVANNAN S}

Assistant Professor, Department of Education, Annamalai University, Annamalai Nagar, Chidambaram, Tamil Nadu-608002, India

\section{ABSTRACT}

The objectives of this study are to find out the higher secondary school students' level of Achievement motivation. The study consists of 200 higher secondary students studying at higher secondary schools located in Nagappattinam District of Tamil Nadu, India. The sample was selected by using simple random sampling technique. For the present investigation, the researcher used the tool constructed and validated by Muthee J.M. \& Immanuel Thomas (2009) to assess the Achievement Motivation of higher secondary students. The finding shows that the higher secondary school students have moderate level of Achievement motivation.

KEYWORDS: Higher Secondary School Students, Achievement Motivation

Received: Feb 26, 2018; Accepted: Mar 15, 2018; Published: Apr 04, 2018; Paper Id.: IJEEFUSAPR20186

\section{INTRODUCTION}

Each day, students navigate the complex worlds of school and society where high levels of achievement are greatly valued. For a student to attain his or her highest level of achievement, motivation must be intact. Fostering positive achievement motivation should be a primary goal of education, not just a means to an end. By focusing on mastery, growth, personal goals, and competence, educators can foster a positive motivational orientation that can lead to a lifelong love of learning. Hence the investigator decided to take this study to know the level of achievement motivation.

Sarita Dahiya and Monika Saini (2015) attempted to understand the gender and knowledge effects of the Achievement Motivation of senior secondary school students. The sample consisted of 200 students from the Govt 10+2 class. Govt, and public schools called. Rohtak Boys Senior Secondary School, Govt. Rohtak, Vaish Boys Senior Public Secondary School, Rohtak and Vaish Girl Sr. High School, Rohtak. The students ranged in age from 16 to 18 years old. The research was carried out by means of a descriptive survey process. Dr. V.P. Bhargava's Achievement Motivation Test (ACMT) and Dr. S.S.'s Mental skill community test. To gather the data, Jalota was used. On the basis of statistical findings, it was concluded that there is a strong positive association between the motivation for achievement and the intellect of male and female students of Govt. Public School. And there is a major gap between male and female Govt students 'achievement. Public colleges, and Mukhtar Ahmad Wani et al. (2015) analysed the level of motivation for achievement, gender disparities in motivation for achievement, academic streams, and to find out the major differences in motivation for achievement of students studying in public and private higher secondary schools. A group of 200 upper secondary school students (100 boys \& 100 girls) was intentionally selected. Descriptive testing methods was used and data was obtained using the scale of motivation for Deo-Mohan achievement. Normal, Std. D, t-test, and ANOVA were performed via SPSS 21. Results 
have shown that 46.5 percent of the survey subjects have an average level of motivation for achievement. Results have also shown that girls perform better on the incentive level for achievement (Boys $M=121.89 \&$ Girls $M=127.82$ ). In achievement motivation across various academic streams, substantial variations were also found. Research also found that, relative to private school students $(M=119.70)$, higher secondary school students studying in government schools have high incentive for achievement ( $\mathrm{M}=125.59)$. The paper concluded that it is important to provide students with a better psycho-social atmosphere to build a deep desire for excellence among our children in the home and school.

Pugalenthi N and Gunasekar N. (2015) examined the degree to which students at secondary level have emotional maturity and academic achievement. For the analysis, the survey research approach was used. The sample of 100 students (50 boys and 50 girls) in the current study was taken using a simple random sampling technique. For data collection, the investigator's Emotional Maturity scale produced in 2015 was used. In addition, for academic achievement marks earned from the State Board in Class X, aided and Matriculation Board for the evaluation of student success. The results of the study showed that: I There is no substantial gap in emotional maturity between boys and girls in secondary level students. (ii) There is no substantial difference in academic achievement between boys and girls at secondary level. Vandana Jain (2015) aims to evaluate and improve the level of motivation for achievement, self-efficacy, academic success, subjective well-being and self-esteem through Dalit Girl Student intervention. The investigator considered the students of SC and ST girls from rural households and low SES families for the purpose of this analysis. The research followed a one-group posttest configuration pre-test. A sample of 44 teenage students residing at the pre-matric government hostel was chosen. It was believed that intervention would increase their motivation for success, self-efficacy, academic performance, subjective well-being and self-esteem. Efficient time management, communication skills, job prospects, leadership preparation, team building, goal setting, interpersonal skills, adolescent psychosocial issues, adolescent physiological development, adolescent nutrition value, oral hygiene, personal hygiene, public speaking, reading habits, memory skills, research habits, how to cope with test habits were part of the intervention. Pre-intervention and post-intervention participants were evaluated. Results for correlated means were evaluated using t. The findings obtained showed that the level of motivation for success, self-efficacy, academic performance, and subjective well-being increased significantly, but there was no substantial increase in self-esteem.

Chamundeswari S. and SanthaKumari. The relationship between motivation for success, study patterns and academic achievement at the secondary level has been examined (2015). The survey approach is used to pick a sample at the secondary level of 457 students. The Achievement Motivation Scale (Beena, 1986) is used to assess the achievement of students through motivation, the Study Habits Inventory (Gopal Rao, 1974) to test student study habits, and the Academic Achievement Test to determine the achievements of students. The findings of the statistical review indicate a strong link between motivation for success, study behaviours, and student performance. There is a substantial disparity between students in various groups of schools and gender linked to motivation for success, study patterns and academic achievement. Sarangi C. (2015) clarified that an individual's achievement motivation is a persistent striving force to achieve success in a competitive situation at a certain level of excellence. An attempt was made in this study to study the impact of achievement encouragement on the academic achievement of tribal and non-tribal group high school students in relation to their sex and locale. A sample of 200 students studying in class IX of ten public high schools in the Goalpara District of Assam was selected for this reason. Gopal Rao's Achievement Incentive Scale tests were administered by them. To research the significance of difference between means and significant relationship between academic achievement motivation, respectively, 't' test and co-efficient of correlation (r) was applied. It was found that tribal-non-tribal and boy- 
girl students did not vary significantly, but urban students displayed high motivation for achievement compared to rural students. In the case of the relationship between motivation for achievement and academic achievement, there was no significant relationship between motivation for achievement and academic achievement of tribal, child, and rural students, but there was a substantial relationship between motivation for achievement and academic achievement of non-tribal, female, and urban students. Portia R. (2016) used social-oriented measurements as constructs as prepared and standardised by Schuler et.al. in the Achievement Incentive Inventory scale. There were 52 objects installed on 17 dimensions of the draught tool designed by the researcher. 9 elements have been dropped in the validation process, going through the processes of determining material validity, construct validity and factorial validity. Finally, the Cronbach Alpha coefficient of 0.729 has defined the reliability of the newly developed scale. The final validated instrument consists of 43 items which are highly valid and reliable.

Rengaraj M. (2016) focused on the attitude of students from the Chennai City School towards encouragement for achievement. It is an examination of whether the incentive for achievement may be shaped by the attitude of students towards school. The primary data was selected from the Higher Secondary Schools to satisfy the study objectives. The researcher therefore contacted the students of the Higher Secondary School from twelve schools in Chennai City with representation from all the regions. This list of twelve schools includes government-run schools, Chennai Municipal Corporation, Private Aided and Private Unassisted schools. It was called the students studying in schools that admit either one sex only, as well as both. The students, that is, both the boys and girls studying medium classes in English and Tamil (native language) were also taken into account. Rao and his associates developed the Achievement Incentive scale, which includes 20 items and the inventory developed by Johnson J.D. It is used for the present study. 50 statements consist of the inventory. The reliability was observed using the Test-Retest method and for the questionnaires used in the analysis, Alpha-Coefficient was also found to have correct interpretation of the results and the same was given. Girls, English medium students, private-assisted school students, Girls school students exclusively have more drive for achievement and more positive attitude towards schools. Shirlin and Sutha.M. P (2017) was conducted in Kanyakumari District to understand the classroom environment and achievement motivation of higher secondary school students. By a stratified random sampling process, the investigator gathered data from 420 higher secondary school students. As instruments, Classroom Environment Inventory and Achievement Incentive Scales have been used. Using suitable statistical techniques such as t-test, ANOVA and correlation, the information obtained was analysed. The findings obtained showed that there is an important significant link between the environment of the classroom and the motivation of higher secondary school students for achievement. Achievement motivation was found to be substantially higher than English medium students depending on the medium of instruction of higher secondary school students.

Dagnew, Asrat (2017) examined the relationship between the attitudes of students towards school education values, motivation for success and academic achievement. A correlation analysis design was then adopted by the researchers. In order to achieve the study objectives, 362 students were taken from grade 9 students of Fasiledes, Angerb, and Azezo secondary schools in North Gondar, Ethiopia using systematic sampling technique. Based on the research objectives and previous observations relevant to the variables used in the analysis, questionnaires were adopted for students. The record offices of the sample high schools received average academic accomplishments.

Vandana N Solanki (2017) examined the motivation for success and study habits of students going to school. The random sample consisted of 240 boys and 240 girls from the districts of Rajkot high and senior secondary schools. 
Investigator Achievement Incentive Inventory developed by Jansari and Research Patterns Inventory developed by M. were used in this study. With N. Palsane and S. Sharma to check the student's enthusiasm for success and study habits. The findings showed that the key influence of urban and rural areas, school types and gender on motivation for achievement and study habits was very important.

The primary and interaction impact of academic motivation (high, average and low academic motivation) and locality (rural and urban) on biology achievement among senior secondary school students was analysed empirically by BabitaLaur (2017). The system of descriptive survey was adopted. A sample of 326 students from private senior secondary school affiliated with CBSE from the Rohtak district of Haryana State was randomly drawn for this reason. To determine the level of academic motivation and accomplishment in biology, the Academic Achievement Motivation Test (AAMT) by Sharma (2005) and a self-developed Biology Achievement Test were administered. With the aid of two-way AVOVA with 3-to-2 factorial architecture, the collected data was analysed. Study findings showed that the key effects of both academic motivation and place were found to be strongly linked to the students' academic success. Furthermore the interaction impact on the achievement of academic motivation \& position was found to be important. The study confirms that academic motivation is critical for students' academic achievement. Thus in helping students to boost their motivation to improve their academic results, it can be concluded by making informative suggestions and recommendations to the authorities, policy makers, colleges, teachers.

Kokila. Kokila. The $\mathrm{K}$ and the Kalaiselvi $\mathrm{K}$. The level of motivation for accomplishment among higher secondary students in the Pudukkottai Educational District of Tamil Nadu State was established (2017). The analysis was limited to 250 samples. 125 of them are male and 125 of them are female. The investigator created a questionnaire to collect the data. The methods used to evaluate the data are descriptive statistics, t-test, The result indicates that the degree of motivation for achievement among students in higher schools is high.

The academic achievement motivation differences among 9th standard students were stated by SangeetaPawar (2017). A sample of 200 students comprising 100 (50 males and 50 females) urban and 100 rural (50 males and 50 females) students were randomly selected from the Hawalbagh Block government schools of the Almora district of Uttarakhand. The methods used in the analysis were the Sharma-standardized Academic Achievement Motivation Test (2010) and a researcher-built Personal Information Schedule. Major disparities between rural and urban students and general and other caste students were revealed by the findings. In the extent of academic achievement encouragement, however no major differences were obtained in the male and female students.

The impacts of teacher effectiveness and motivation on the academic achievement of students in science education in secondary and high schools in Iran and Russia were examined by SecilBal-Tastan et al. (2018) using academic success scale motivation (alpha $=0.89$ ) and teacher self-efficacy scale (alpha $=0.91$ ) as assessment methods and achievement tests in science education. The mathematical programme was used to test two hypotheses. Comparative tests were conducted using the t-test to assess the students' ethnic disparities in terms of their academic achievement. The findings showed that gender differences were not significant, but the disparity in ethnicity was significant in terms of the academic performance of students in science education. Significant effects of teacher self-efficacy and motivation on academic achievement in science education were also recorded in other results. It discussed and addressed consequences, suggestions and guidelines for students, teachers, school administrators, parents, government, education counsellors, etc.

Yeah. Rajina, G. The achievement motivation of higher secondary school students in Tiruvallur District was 
examined by P.Karnan (2018). 300 higher secondary school students were randomly selected by different schools in the tiruvallur district in this study adopted the normative survey method of research participants. Robinson evaluated at 0.05 and 0.01 level of significance to establish the testing methods used for data collection was accomplishment motivation scale. The level of motivation for achievement of higher secondary students has been found to be moderate in nature. The results showed that the motivation for achievement of higher secondary students is a positive relationship. With regard to gender, location, medium of instructions, type of family, type of management, mother qualifications, parental involvement of higher secondary school students, significant impact exists.

\section{OBJECTIVES OF THE STUDY}

- To find out whether there is any significant difference between Male and Female higher secondary students with respect to their achievement motivation.

- To find out whether there is any significant difference between rural and urban higher secondary students the with respect to their achievement motivation.

- To find out whether there is any significant difference between Arts and Science students with respect to their achievement motivation.

\section{HYPOTHESES OF THE STUDY}

- There is a significant difference between Male and Female higher secondary students with respect to their achievement motivation.

- There is a significant difference between rural and urban higher secondary students the with respect to their achievement motivation.

- There is a significant difference between arts and science students with respect to their achievement motivation.

\section{Sample of the Study}

The present study consists of 200 higher secondary students studying at higher secondary schools located in Nagappattinam district of Tamil Nadu. The sample was selected by using simple random sampling technique.

\section{Tool Used}

For the present investigation, the researcher used the tool constructed and validated by Muthee J.M. \& Immanuel Thomas (2009) to asses the Achievement Motivation of higher secondary students.

In order to find out the Achievement motivation of Higher secondary School students, the mean and S.D have been calculated.

Table 1: The Mean and Standard Deviation of Achievement Motivation Scores of Higher Secondary School Students

\begin{tabular}{|c|c|c|c|c|}
\hline \multirow{2}{*}{ Demographic Variable } & Sub Sample & N & Mean & SD \\
\hline \multirow{2}{*}{ Gender } & Male & 91 & 48.59 & 23.376 \\
\cline { 2 - 5 } & Female & 109 & 62.59 & 27.269 \\
\hline \multirow{2}{*}{ Locality } & Rural & 118 & 58.93 & 27.080 \\
\cline { 2 - 5 } & Urban & 82 & 52.32 & 25.162 \\
\hline \multirow{2}{*}{ Group } & Arts & 137 & 60.44 & 26.601 \\
\cline { 2 - 5 } & Science & 63 & 47.05 & 23.835 \\
\hline \multicolumn{2}{|c|}{ Entire } & 200 & 56.22 & 26.448 \\
\hline
\end{tabular}




\section{Entire Sample}

It is evident from the above Table the calculated mean score of entire sample indicates that the higher secondary school students have Moderate level of Achievement motivation

\section{Gender}

The mean score of male and female student's Achievement motivation indicate that both male and female students have Moderate level of Achievement motivation.

\section{Locality}

The mean score of rural and urban school student's Achievement motivation. These mean scores indicate that both rural and urban school students have Moderate level of Achievement motivation.

\section{Type of School}

The mean scores of Government, Private and aided school students. It indicates that the government, private and aided school students have Moderate level of Achievement motivation.

\section{Group}

The mean score of Arts and Science students' Achievement motivation indicate that both Arts and Science students have Moderate level of Achievement motivation.

\section{Community}

The mean scores of $\mathrm{OC}, \mathrm{BC}, \mathrm{MBC}$ and SC/ST students indicates that the $\mathrm{OC}, \mathrm{BC}, \mathrm{MBC}$ and SC/ST students have Moderate level of Achievement motivation.

\section{Null Hypothesis}

There is no significant difference between Male and Female students with respect to their Achievement motivation.

In order to test the above Null hypothesis ' $t$ ' value is calculated.

Table 2: Significance of Difference between Male and Female Students with Respect to their Achievement Motivation

\begin{tabular}{|c|c|c|c|c|c|}
\hline Gender & $\mathbf{N}$ & Mean & SD & t - Value & Significance at 0.05 Level \\
\cline { 1 - 4 } Male & 91 & 48.59 & 23.376 & \multirow{2}{*}{3.907} & Significant \\
\hline Female & 109 & 62.59 & 27.269 & & S \\
\hline
\end{tabular}

From the above table, since the ' $\mathrm{t}$ ' value is significant at 0.05 level, the above Null hypothesis is rejected and it is concluded that there is significant difference between Male and Female students with respect to their Achievement motivation.

\section{Null Hypothesis}

There is no significant difference between rural and urban located students in their Achievement motivation.

In order to test the above Null hypothesis ' $t$ ' value is calculated. 
Table 3: Significance of Difference between Rural and Urban School Students with Respect to their Achievement Motivation

\begin{tabular}{|c|c|c|c|c|c|}
\hline Locality & N & Mean & SD & \multirow{2}{*}{ t-Value } & $\begin{array}{c}\text { Significance at 0.05 } \\
\text { Level }\end{array}$ \\
\cline { 1 - 3 } Rural & 118 & 58.93 & 27.080 & \multirow{2}{*}{1.77} & Not significant \\
\hline Urban & 82 & 52.32 & 25.162 & \\
\hline
\end{tabular}

From the above table, since the 't' value is not significant at 0.05 level, the above Null hypothesis is accepted and it is concluded that there is no significant difference between rural and urban students with respect to their Achievement motivation.

\section{Null Hypothesis}

There is no significant difference between Students in their Achievement motivation with respect to their Arts and science Students.

In order to test the above Null hypothesis ' $t$ ' value is calculated.

Table 4: Significance of Difference between Arts and Science Students with Respect to their Achievement Motivation

\begin{tabular}{|c|c|c|c|c|c|}
\hline Group & N & Mean & SD & t-Value & $\begin{array}{c}\text { Significance } \\
\text { at 0.05 Level }\end{array}$ \\
\hline Arts & 137 & 60.44 & 26.601 & \multirow{2}{*}{3.56} & Significant \\
\hline science & 63 & 47.05 & 23.835 & \\
\hline
\end{tabular}

From the above table, since the ' $t$ ' value is not significant at 0.05 level, the Null hypothesis is rejected and it is concluded that there is significant difference between Arts and science Students with respect to their Achievement motivation.

\section{IMPORTANT FINDINGS}

Following are the important findings arrived by the investigator based on the data collected and analyzed.

- The higher secondary school students have moderate level of Achievement motivation

- There is significant difference between Male and Female students with respect to their Achievement motivation.

- There is significant difference between rural and urban students with respect to their Achievement motivation.

- There is significant difference between Arts and science Students with respect to their Achievement motivation.

\section{CONCLUSIONS}

This study reveals some of the important results about the achievement motivation of higher secondary school students. On the basis of the results efforts are to be taken to inculcate positive expectations and attitude and self belief among all the students to have peace full life and to become socially accepted person. Teachers and Parents should understand the importance of Achievement Motivation for the Children and should be cautious about their level of Achievement Motivation.

\section{REFERENCES}

1. Adikwu Victoria Ogwa (2018) Family Factors as Predictors of Academic Achievement Motivation among Secondary Schools Students in North Central Zone of Nigeria, International Journal of Education and Research, 6, 2, 157-170. 
2. BabitaLaur (2017) Achievement among Senior Secondary School Students: A Comparative Study on the Basis of Academic Motivation and Locality, GALAXY International Interdisciplinary Research Journal, 5, 3, 1-13.

3. Chandra Shekhar and Rajinder Kumar (2016) Gender differences in achievement motivation, self efficacy academic stress and academic achievement of secondary school students, International Journal of Applied Social Science, 3, 5, $117-124$.

4. Dagnew, Asrat (2017) The Relationship between Students' Attitudes towards School, Values of Education, Achievement Motivation and Academic Achievement in Gondar Secondary Schools, Ethiopia, Research in Pedagogy, 7, 1, $30-42$.

5. Gunasekar N and Pugalenthi N. (2015) A Study On Emotional Maturity And Academic Achievement Of Students At Secondary Level, Shanlax International Journal of Education, 3, 4, 7-13.

6. Kokila. K and Kalaiselvi K. (2017) A Study on Achievement Motivation among Higher Secondary School Students in Pudukkottai Educational District, International Journal of Informative \& Futuristic Research, 4, 9, 7588-7593.

7. Mrinmoy Roy (2016) Procrastination and Achievement Motivation amongst Higher Secondary Students in Nadia District, International Journal of Multidisciplinary Studies, 1, 1, 40-58.

8. Mukhtar Ahmad Wani et al., (2015) Achievement Motivation: A Study with reference to certain Demographic Variables, Journal of Education and Social Sciences, 3, 1, 1-10.

9. Portia R. (2016) Developing a Valid Rating Scale for Measuring Achievement Motivation of Higher Secondary Students, International Journal of Economic and Business Review, 4, 12, 5-14.

10. Rajina, G. and P.Karnan (2018) A Study on Achievement Motivation of Higher Secondary School Students in Tiruvallur District, International Educational Scientific Research Journal International Indexed Journal 4, 3.

11. Rengaraj M. (2016) The impact of attitude towards Achievement Motivation among school students in Chennai city, Tamil Nadu, India, Research Journal of Pharmaceutical, Biological and Chemical Sciences, 7, 5, 2627-2643.

12. SangeetaPawar (2017) A Study of Academic Achievement Motivation among Secondary School students, Scholarly Research Journal for Interdisciplinary Studies, 4, 36, 6646-6651.

13. SanthaKumari and Chamundeswari S (2015) Achievement Motivation, Study Habits and Academic Achievement of Students at the Secondary Level, International Journal of Emerging Research in Management \&Technology, 4, $10,7-13$.

14. Sarangi C. (2015) Achievement Motivation of the High School Students: A Case Study among different Communities of Goalpara District of Assam, Journal of Education and Practice, 6, 19, 140-144.

15. SaritaDahiya and Monika Saini, (2015) A Comparative Study of Achievement Motivation of Senior Secondary School Students in Relation to Gender and Intelligence, https://ideas.repec.org/p/vor/issues/2014-09-03.html

16. SecilBal-Tastan et al., (2018) The Impacts of Teacher's Efficacy and Motivation on Student's Academic Achievement in Science Education among Secondary and High School Students, EURASIA J. Math., Sci Tech. Ed;14(6):2353-2366.

17. Steinberg, L. (1996). Ethnicity and adolescent achievement, American Educator, 20(2), 28-35.

18. Sutha.M and Shirlin. P (2017) Classroom Climate and Achievement Motivation of Higher Secondary School Students In Kanyakumari District, International Journal of Research - Granthaalayah, 5, 3, 23-32.

19. Vandana Jain (2015) Achievement Motivation, Self Efficacy, Academic Performance, Subjective Well-Being and Self Esteem among Dalit Girl Students, University Grants Commission, Final Report, Minor Research Project.

20. Vandana N Solanki (2017) A Comparative Study Achievement Motivation and Study Habits of School Going Students on Rajkot District Area, The International Journal of Indian Psychology, 4, 4, 41-53. 
21. Thirunavalavan, $T \&$ Venkataraman, S. (2017), Higher Secondary Students' Achievement in Chemistry, their Self-esteem, SelfActualization and certain External Factors, International Journal of Academic Research Reflector 6 (5), 60-66.

22. Senthuran, D\& Venkataraman, S. (2017), Personal, peer and parents' psychological factors and higher secondary students' achievement in zoology, International Journal of Innovative Research Explorer 6 (2), 53-56.

23. Senthuran, D, \& Venkataraman, S. (2017), Construction and validation of the State of External Factor Scale (SEFS), International Journal of Innovative Research Explorer 6 (1), 10-15.

24. Senthuran, D \& Venkataraman, S. (2017), Construction and validation of a tool measuring the personal peer and parents' psychological factors of higher secondary students, International Journal of Academic Research Reflector 6 (2), 16-21.

25. Venkataraman, S. (2016), Views on New Education Policy framework-2016 with regard to Curriculum Renewal, Examination Reforms and Governance Reforms in Higher Education, Research Inspiration 4 (1), 91-95.

26. Venkataraman, S. (2016), Views on New Education Policy framework-2016 with Regard to Restoration of Detention Policy between Class Six to Nine, Merger and Consolidation of Schools, International Journal for Research in Education (IJRE) 5 (3), 14-16.

27. Venkataraman, S. (2016), A study on profile update status of teaching staff in Annamalai University Website, Journal of Contemporary Educational Research and Innovations 5 (3), 157-160.

28. Venkataraman, S. (2016), Study on the data of Newly selected assistant professors for Tamil and English subjects for Arts and Science colleges of Tamilnadu, International Journal of Innovative Research Explorer 4 (1), 27-29.

29. Woolfolk, A. (2004). Educational Psychology. Boston: MA:Allyn \& Bacon. 

